\title{
When the Best of Intentions Leads to Bad Outcomes
}

Gary W. Jay · Howard A. Heit · Douglas L. Gourlay

Received: September 24, 2018 / Published online: April 2, 2019

(C) The Author(s) 2019

\section{ABSTRACT}

There is no question that the opioid use problem in America has reached unacceptable proportions. What is in question, however, is the best way to address this problem. Unfortunately, this is a multidimensional problem that will not be solved with a simple unidimensional solution. This commentary examines the multidimensional nature of this problem and the resultant guidelines that have been proposed to address it. There is a cautionary tale of the historical dangers of applying an "obvious" solution to a problem, only to find that more investigation and an iterative approach can actually lead to the correct solution. In particular, the authors question the wisdom of implementing guidelines that have no provisions for re-examination, to assess both intended as well as unintended consequences that

Enhanced digital features To view enhanced digital features for this article go to https://doi.org/10.6084/ m9.figshare.7861994.

\section{G. W. Jay $(\varangle)$}

Department of Neurology, University of North Carolina, Chapel Hill, NC, USA

e-mail:drgwjay@aol.com

H. A. Heit

Private Practice, Reston, VA, USA

D. L. Gourlay

Private Practice, Hamilton, ONT, Canada might occur. This is the standard for good evidence-based guideline development and implementation. To do less, even under such dire circumstances as these, is to provide less than optimum medical care.

Keywords: Guideline development; Illicit opioids; Opioid use disorder; Prescription drug problem

\section{INTRODUCTION}

Without question, we are reaching a critical point in the impact of opioids on society. We can debate the magnitude of the problem and we certainly can debate the solutions to address the problem, yet we are currently seeing over 115 opioid-related deaths per day [1], with every indication that this number is going up. This is likely a conservative estimate since this data does not include those former medical users who have been arbitrarily tapered from their medically supplied opioids and have since died.

Recently, the government has introduced a set of guidelines to advise the medical community on how to more 'safely' treat chronic pain; including guidance around upper limits in daily equivalents of opioid-related products [2]. While an important first step, it is not without its critics.

First, the CDC guideline is largely targeting 'new chronic pain patients' who are largely 
opioid-naive, leaving those patients who have been long-term opioid users and their prescribers with the difficult challenge of compliance with these recommendations. Worse still, some state regulatory authorities are using these 'guidelines' as de facto regulations [3], effectively tying the hands of prescribers who risk decompensating an otherwise stable patient who happens to exceed these recommended limits. This is despite the 2017 guidelines adopted by the Federation of State Medical Boards, which clearly emphasize the importance of clinical judgement on a case-by-case basis [4].

Some prescribers are facing significant legal exposure, including criminal prosecution, loss of prescribing privileges, and in many cases, are simply deciding to stop altogether the use of opioids in the treatment of pain. Sadly, in all of these examples, there is really no evidence that these interventions are having a positive impact on the problem at hand; there is at least concern that they may be having a significant negative impact on the problem [5].

Again, logic says that reducing the medical availability of the opioid class of drugs must have a positive impact on decreasing the death rate related to this class of drugs. While it may have been true 15 or 20 years ago, it is naive to think that reduced availability will only have positive effects.

The real question here is; what problem are we trying to solve? More importantly, is the question of how to accomplish this while maintaining the availability of this class of medication for the appropriate treatment of chronic, intractable pain.

Despite all our 'best efforts' to date, we still have a massive per-diem death rate from opioids, both licit and illicit [5]. Unfortunately, it is becoming apparent that licit and illicit opioids are probably not best thought of as separate problems but evaluated as interdependent variables of a common problem. We are simply not getting the balance right!

We know from the literature that as opioid doses go up, risk increases [6]. It stands to reason that if we keep these doses lower, risk and so death will be positively impacted; but is this true in all cases? Certainly in those who are opioid-naive, this truth may apply, but what about the patients who are already on doses vastly more than any current recommended limits? Might arbitrary dose reductions, tapers, or product reformulation lead not to a reduction in death, but rather an increase? That would seem to be the case when we examine the New York State experience [7]. Again, it might be tempting to think that this population is those who suffer from a substance use disorder, but we really have little evidence to support this assertion. Many of these patients will simply find that their previously managed pain syndromes are no longer bearable; in others, their iatrogenically driven physical dependence on the opioid class of drugs leads to an unbearable level of opioid withdrawal with little hope for relief in sight. For some, death by suicide may seem to be the best option. For others, they may turn to the street to get the medication that they need. Unfortunately, for those who take the this option, their first foray into self-help may be their last, as much of the supply of opioids on the street are counterfeit drugs containing ultra-potent opioids such as fentanyl or carfentanyl [7, 8]. Again, dead is still dead; hardly a win by any reasonable measure.

\section{OBVIOUS DOESN'T ALWAYS MEAN RIGHT}

There have been many examples in the history of medicine that illustrate the need for caution when applying simple logic to the advancement of medical science. Two more examples are presented below.

Clofibrate was a drug developed in the 1950s as a cholesterol-reducing agent in the treatment of cardiovascular disease [9]. As such, patients on the active treatment arm of the clofibrate studies showed a dramatic decrease in total cholesterol as compared to the placebo arm of the study. In this sense, the drug was a complete success. Over time, it was decided to examine these results in slightly different terms: which study arm lived longer? Of course, we now know that total cholesterol reduction is not the desired goal; that some cholesterol was in fact "good" cholesterol. This is a great example of 
the importance of critical thinking when defining markers of success.

Retrolental fibroplasia (RLF) and the importance of oxygen concentration in the treatment of prematurely born neonates is another example of logic and common sense resulting in worsened rather than improved outcomes $[10,11]$

This disorder was commonly seen early in maternal-fetal medicine, with the treatment of pulmonary immaturity in premature babies. The limited capacity of the immature lungs to exchange oxygen was largely treated with highly enriched oxygen atmospheres. The goal was to overcome the limited ability to maintain 'normal' oxygen saturations by enriching the baby's supply of supplemental oxygen. Unfortunately, one of the other complications of the premature baby's immaturity was an ocular disorder called retrolental fibroplasia [10, 11]. At the time, there was no suspected relationship between this disorder and the use of high-concentration oxygen. It was only through carefully designed clinical trials that it was discovered that it was in fact the concentrated oxygen that was causing this disorder. Counterintuitive and very difficult to sort out: many care givers felt it unethical to allow the oxygen saturations to fall in the "low-flow" oxygen group. This frustrated the efforts to study this. Over time, it was discovered that there was an optimal oxygen level to maintain that minimized the risk of RLF while still having acceptable premature survival rates.

In some respects, the above example highlights the dilemma facing society today; too much of something can be harmful but not enough can be deadly. We need to find the correct balance of education to adequately equip the medical community to more responsibly use these potent agents while ensuring that the regulatory framework in which medicine is practiced is not overly intrusive but rather supportive of medical best practices.

The opioid crisis today may be less about inappropriate/indiscriminate prescribing than it is about indiscriminate restriction to medical access of the opioid class of drugs-leading to very dangerous 'self-remedies' such as sharing/ borrowing of medications or even purchasing illicit/counterfeit medications/drugs from the street.

We are not pro or con opioid therapy: that question is beyond the scope of this article. We are, however, critical of shoddy guideline development and implementation. Without the iterative process implicit in evidence-based medicine-keeping what seems to work and modifying/deleting that which does not, it will be very difficult to stem the tide of opioid-related deaths in America.

\section{CONCLUSIONS}

To be clear, we are pro evidence-based medicine. No question "something needs to be done." We must remember, however, that interventions, no matter how well intended or seemingly appropriate on their face, need to be constantly evaluated in terms of their intended as well as unintended outcomes. As we have seen before, sometimes the treatment may be worse than the disease! Without critical evaluation of both intended as well as unintended consequences, we cannot rationally solve this problem.

\section{ACKNOWLEDGEMENTS}

Funding. No funding or sponsorship was received for the construction or publication of this article.

Authorship. All named authors meet the International Committee of Medical Journal Editors (ICMJE) criteria for authorship for this article, take responsibility for the integrity of the work, and have given their approval for this version to be published

Disclosures. Gary W. Jay, Howard A. Heit, and Douglas L. Gourlay have nothing to disclose.

Compliance with Ethics Guidelines. This article is based on previously conducted studies and does not contain any studies with human 
participants or animals performed by any of the authors.

Open Access. This article is distributed under the terms of the Creative Commons Attribution-NonCommercial 4.0 International License (http://creativecommons.org/licenses/ by-nc/4.0/), which permits any noncommercial use, distribution, and reproduction in any medium, provided you give appropriate credit to the original author(s) and the source, provide a link to the Creative Commons license, and indicate if changes were made.

\section{REFERENCES}

1. Hedegaard H, Warner M, Minino AM. Drug overdose deaths in the United States, 1999-2016. NCHS Data Brief. 2017;294:1-8.

2. Houry D, Baldwin G. Announcing the CDC guideline for prescribing opioids for chronic pain. J Safety Res. 2016;57:83-4.
3. Policy for the use of opioids for the treatment of pain. 2017.

4. Guidelines for the Chronic use of Opioid Analgesics. 2017, Federation of State Medical Boards.

5. Schatman ME, Ziegler SJ. Pain management, prescription opioid mortality, and the CDC: is the devil in the data? J Pain Res. 2017;10:2489-95.

6. Liang Y, Turner BJ. Assessing risk for drug overdose in a national cohort: role for both daily and total opioid dose? J Pain. 2015;16(4):318-25.

7. Evans WN, Lieber E, Power, P. How the reformulation of OxyContin ignited the heroin epidemic. Review of Economics and Statistics (in press).

8. Ingraham C. How an 'abuse-deterrent' drug created a heroin epidemic; in Washington Post. 2017.

9. Oliver M. The clofibrate saga: a retrospective commentary. Br J Clin Pharmacol. 2012;74(6):907-10.

10. Tin W, Gupta S. Optimum oxygen therapy in preterm babies. Arch Dis Child Fetal Neonatal Ed. 2007;92(2):F143-7.

11. Tin W. Oxygen therapy: 50 years of uncertainty. Pediatrics. 2002;110(3):615-6. 